\title{
Response of plasma matrix metalloproteinases and tissue inhibitor of metalloproteinases to stent-graft surgery for descending thoracic aortic aneurysms
}

\author{
Mario Monaco, MD, Paolo Stassano, MD, Luigi Di Tommaso, MD, and Gabriele lannelli, MD
}

From the Department of Cardiac Surgery, University of Naples "Federico II," Naples, Italy.

Received for publication March 18, 2007; revisions received April 19, 2007; accepted for publication May 11, 2007.

Address for reprints: Mario Monaco, MD, Via A. Falcone, 258-80127 Naples, Italy (E-mail: mario.monaco@unina.it).

J Thorac Cardiovasc Surg 2007;134:925-31

$0022-5223 / \$ 32.00$

Copyright $(9) 2007$ by The American Association for Thoracic Surgery

doi:10.1016/j.jtcvs.2007.05.044
Objective: The role of matrix metalloproteinases and their tissue endogenous inhibitors has been documented in abdominal aortic aneurysms, but few articles have investigated their role after thoracic aortic aneurysm treatment. Our report investigates matrix metalloproteinases and tissue endogenous inhibitor-1 plasmatic changes in patients who have undergone endovascular aneurysm repair for descending thoracic aortic aneurysms and assesses their clinical significance.

Methods: Thirty-two patients with thoracic aortic aneurysms who underwent endovascular aneurysm repair were compared with 25 healthy volunteers. Plasma matrix metalloproteinase-3/matrix metalloproteinase- 9 and tissue endogenous inhibitor-1 values were determined by an enzyme-linked immunosorbent assay method at a predetermined time interval.

Results: The preoperative levels of matrix metalloproteinases in the endovascular aneurysm repair group were 3-fold and 2-fold higher than those in the control group $(P<.001$ and .02 , respectively). Matrix metalloproteinase values normalized after endovascular aneurysm repair, whereas patients experiencing endoleaks had higher matrix metalloproteinase values and matrix metalloproteinase-9/tissue endogenous inhibitor-1 ratio compared with the control group $(P=.003,<.001$, and $=.02$, respectively, at 1-month follow-up). These values normalized with the resolution of the endoleak.

Conclusions: Plasma matrix metalloproteinase values are increased in patients with thoracic aortic aneurysms, along with reduced tissue endogenous inhibitor-1 expression. Successful endovascular aneurysm repair results in values normalization, whereas high levels persist in patients with endoleaks. The enzyme-linked immunosorbent assay test is a simple and reliable technique that is useful to assess the efficacy of endovascular aneurysm repair and to detect endoleaks.

$\mathrm{T}$ horacic aortic aneurysms (TAAs) are a serious and potentially lethal disease with high mortality and morbidity rates. ${ }^{1}$ Even if atherosclerosis plays an important role in the genesis of TAAs, their formation and progression are a multifactorial process involving both cellular and extracellular processes that have not been extensively examined. ${ }^{2}$

Matrix metalloproteinases (MMPs) are a group of proteases that play an important role in the protein synthetic-lytic equilibrium of connective tissue. The extracellular matrix (ECM) degradation in aneurysm tissue is in part caused by MMPs. In addition, it has been demonstrated that the endogenous tissue inhibitor of metalloproteinases (TIMP) plays a role in the modulation of MMP activity. ${ }^{3}$ MMP-3 and MMP-9 are the most important and widespread MMPs in abdominal aortic aneurysm (AAA) wall tissue, and although their role in the destructive rearrangement of the elastic aortic wall components has been well demonstrated in AAA models, ${ }^{4-8}$ few reports have demonstrated their role in TAAs. ${ }^{9-12}$ Moreover, although the role of MMPs and TIMPs as a marker of successful aneurysm exclusion after 


\section{Abbreviations and Acronyms}

AAA $=$ abdominal aortic aneurysm

CT = computed tomography

$\mathrm{ECM}=$ extracellular matrix

ELISA $=$ enzyme-linked immunosorbent assay

$\mathrm{EVAR}=$ endovascular aneurysm repair

MMP = matrix metalloproteinase

TAA $=$ thoracic aortic aneurysm

TIMP $=$ tissue inhibitor of metalloproteinases

endovascular aneurysm repair (EVAR) of AAAs has been elucidated, ${ }^{5-7}$ no study to date has determined their changes after EVAR of TAAs and their influence on the clinical outcome of patients.

The aim of our report is 2-fold: (1) to investigate the changes of MMP-3, MMP-9, and TIMP-1 in the blood plasma of patients who have undergone EVAR for descending TAAs and (2) to assess their clinical significance.

\section{Materials and Methods}

From June 2003 to June 2005, 32 patients (group A) who underwent EVAR for TAA were compared with 25 healthy volunteers
TABLE 1. Clinical characteristics of control group and endovascular aneurysm repair group

\begin{tabular}{lccl}
\hline Clinical variables & $\begin{array}{c}\text { EVAR group } \\
\text { (n = 32) }\end{array}$ & $\begin{array}{c}\text { Control group } \\
(\mathbf{n}=\mathbf{2 5})\end{array}$ & $\boldsymbol{P}$ \\
\hline Age, y & $68.45 \pm 5.78$ & $66.07 \pm 1.29$ & .07 \\
Male & $27(84.4 \%)$ & $19(76.0 \%)$ & .5 \\
Diabetes & $9(28.1 \%)$ & $5(20.0 \%)$ & .6 \\
Hypertension & $21(65.6 \%)$ & $14(56.0 \%)$ & .5 \\
Ischemic heart disease & $4(12.5 \%)$ & - & .07 \\
Previous CABG & $3(9.4 \%)$ & - & .1 \\
Previous vascular surgery & $3(9.4 \%)$ & - & .1 \\
Renal insufficiency (creatinine & $6(18.7 \%)$ & - & .2 \\
$\quad>1.5$ mg/dL) & & & \\
Chronic obstructive pulmonary & $13(40.6 \%)$ & $4(16.0 \%)$ & .08 \\
$\quad$ disease & & & \\
ASA score & $1.72 \pm 0.5$ & $1.21 \pm 0.4$ & .0005 \\
\hline
\end{tabular}

$E V A R$, Endovascular aneurysm repair; $C A B G$, coronary artery bypass graft; $A S A$, American Society of Anesthesiologists. Data are reported as mean \pm standard deviation or $\mathrm{n}(\%)$.

(group B). The 2 groups were matched for age and sex. Both EVAR and control groups were not on a regimen of statins, acetylsalicylic acid, or angiotensin-converting enzyme inhibitors, or any anti-inflammatory therapy that might affect MMP secretion.

TABLE 2. Matrix metalloproteinase-3, matrix metalloproteinase-9, tissue inhibitor of metalloproteinase-1 plasma levels, and matrix metalloproteinase-9/tissue inhibitor of metalloproteinase-1 ratio at five different time points

\begin{tabular}{|c|c|c|c|c|c|c|}
\hline & $\begin{array}{c}\text { Control group } \\
\text { (20 patients) }\end{array}$ & $\begin{array}{l}\text { EVAR group } \\
\text { (16 patients) }\end{array}$ & $\begin{array}{c}\text { Endoleak group } \\
\text { (4 patients) }\end{array}$ & $\begin{array}{c}P \text { value } \\
\text { EVAR vs control }\end{array}$ & $\begin{array}{c}P \text { value } \\
\text { endoleak vs } \\
\text { control }\end{array}$ & $\begin{array}{c}P \text { value } \\
\text { endoleak vs } \\
\text { EVAR }\end{array}$ \\
\hline \multicolumn{7}{|l|}{ MMP-3 } \\
\hline Preoperative & $136.0 \pm 73.5$ & $392.2 \pm 148.2$ & $379.5 \pm 14.4$ & $<.001$ & $<.001$ & NS \\
\hline Discharge & $134.4 \pm 74.5$ & $154.6 \pm 61.5$ & $228.3 \pm 15.5$ & NS & .001 & .01 \\
\hline $1 \mathrm{mo}$ & $133.8 \pm 73.6$ & $152.1 \pm 61.6$ & $326.0 \pm 35.0$ & NS & .003 & .002 \\
\hline $3 \mathrm{mo}$ & $135.7 \pm 74.4$ & $145.2 \pm 86.0$ & $224.3 \pm 34.4$ & NS & .04 & NS \\
\hline $6 \mathrm{mo}$ & $134.4 \pm 73.2$ & $146.8 \pm 87.9$ & $188.0 \pm 6.8$ & NS & NS & NS \\
\hline \multicolumn{7}{|l|}{ MMP-9 } \\
\hline Preoperative & $63.1 \pm 38.7$ & $124.1 \pm 58.0$ & $113.6 \pm 29.4$ & .02 & .02 & NS \\
\hline Discharge & $64.8 \pm 39.6$ & $97.3 \pm 57.7$ & $126.0 \pm 19.7$ & NS & .01 & NS \\
\hline $1 \mathrm{mo}$ & $64.4 \pm 39.8$ & $92.3 \pm 55.2$ & $150.0 \pm 15.6$ & NS & $<.001$ & .02 \\
\hline $3 \mathrm{mo}$ & $63.8 \pm 40.0$ & $70.4 \pm 46.2$ & $130.3 \pm 32.2$ & NS & .02 & .02 \\
\hline $6 \mathrm{mo}$ & $65.3 \pm 40.8$ & $70.9 \pm 50.8$ & $83.8 \pm 27.2$ & NS & NS & .04 \\
\hline \multicolumn{7}{|l|}{ TIMP } \\
\hline Preoperative & $11.1 \pm 7.6$ & $5.4 \pm 3.8$ & $5.9 \pm 1.5$ & .04 & NS & NS \\
\hline Discharge & $11.2 \pm 8.0$ & $8.1 \pm 4.8$ & $8.8 \pm 2.5$ & NS & NS & NS \\
\hline $1 \mathrm{mo}$ & $10.9 \pm 7.5$ & $8.8 \pm 5.4$ & $7.5 \pm 2.6$ & NS & NS & NS \\
\hline $3 \mathrm{mo}$ & $11.2 \pm 7.8$ & $12.5 \pm 7.9$ & $14.5 \pm 6.1$ & NS & NS & NS \\
\hline $6 \mathrm{mo}$ & $10.5 \pm 7.3$ & $11.3 \pm 8.8$ & $14.8 \pm 3.8$ & NS & NS & NS \\
\hline \multicolumn{7}{|l|}{ MMP/TIMP } \\
\hline Preoperative & $8.7 \pm 7.0$ & $24.5 \pm 9.7$ & $15.0 \pm 3.6$ & .003 & .005 & NS \\
\hline Discharge & $8.8 \pm 6.9$ & $14.4 \pm 8.4$ & $22.1 \pm 8.4$ & .01 & .008 & .01 \\
\hline $1 \mathrm{mo}$ & $8.3 \pm 5.2$ & $13.9 \pm 6.9$ & $22.2 \pm 4.7$ & .01 & .02 & .01 \\
\hline $3 \mathrm{mo}$ & $8.1 \pm 6.8$ & $6.3 \pm 1.2$ & $9.7 \pm 2.3$ & NS & NS & .006 \\
\hline $6 \mathrm{mo}$ & $9.0 \pm 6.8$ & $7.2 \pm 3.6$ & $8.7 \pm 5.3$ & NS & NS & NS \\
\hline
\end{tabular}

EVAR, endovascular aneurysm repair; TIMP, tissue inhibitor of metalloproteinases; NS, not significant. 
口Control group घEVAR group aEndoleak group

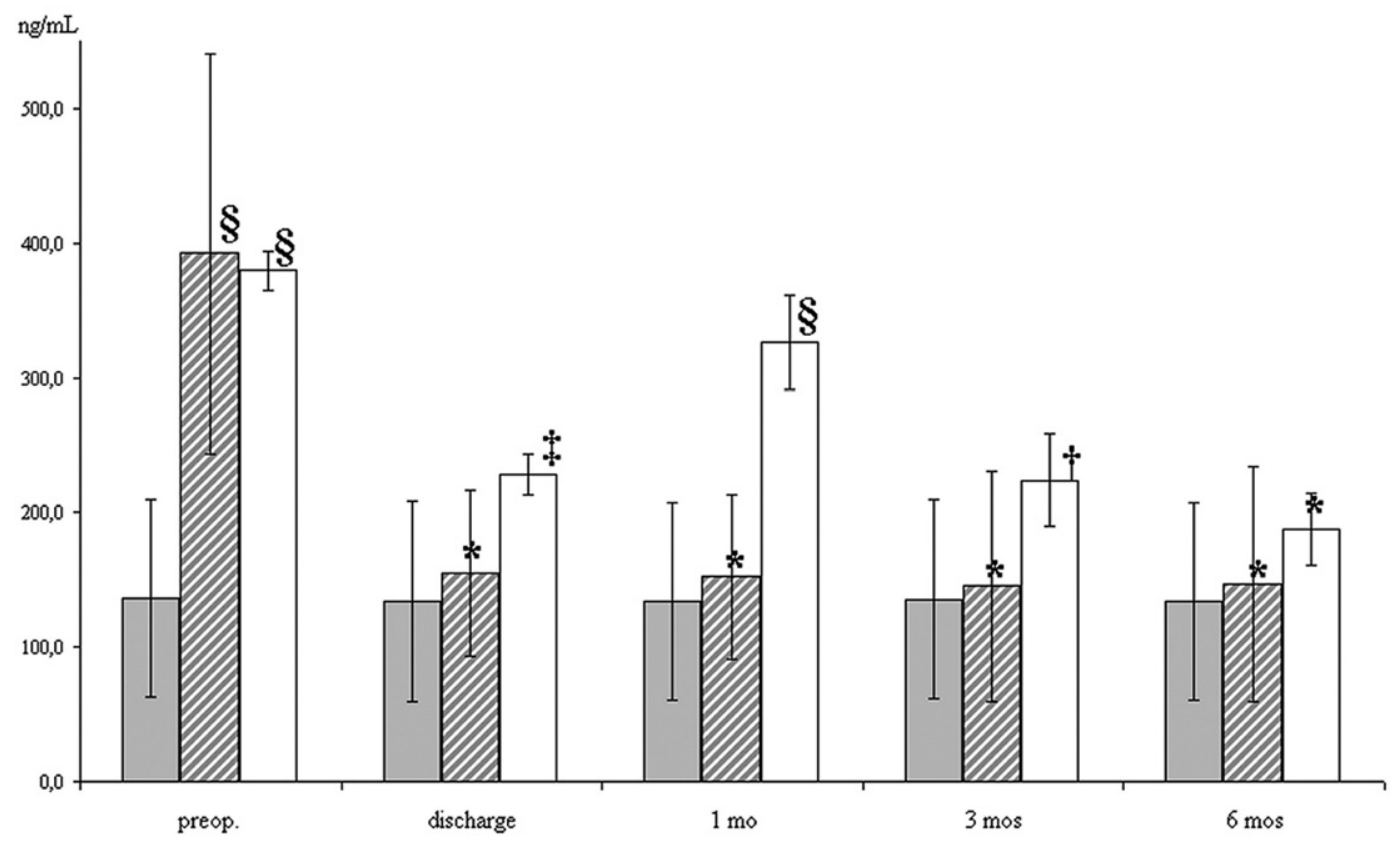

Figure 1. MMP-3 plasma value concentrations before and during follow-up after stent-graft placement. *Not significant; $\uparrow<.05 ; \ddagger<.01 ; \S<.001$. EVAR, Endovascular aneurysm repair; MMP, matrix metalloproteinase.

Approval for the study was obtained from the institutional review board, and informed consent was granted by each patient. In control group B, the absence of aortic and/or peripheral vascular disease was assessed by spiral computed tomography (CT) scan and Color-Duplex scanner. Demographic and clinical data of the patients enrolled in the study are listed in Table 1. Group A had only atherosclerotic TAAs; patients with thoracic aorta dissection, transection, or Marfan syndrome were excluded.

The diagnosis of TAAs in group A was obtained by CT scan. Evaluation of aneurysm length, diameter, quality, dimension of the proximal and distal necks, diameter of the access vessels, and presence or absence of mural thrombus at the necks were assessed. Risk assessment criteria were evaluated according to the American Society of Anesthesiologists score. ${ }^{13}$

Blood samples for plasma MMP-3, MMP-9, and TIMP-1 values determination were collected from each patient of group A by venous puncture into an ethylenediamine tetraacetic acid bloodcollection tube before the stent-graft procedure, at hospital discharge, and at 1, 3, and 6 months of follow-up. In control group B, blood samples were obtained at days 1 and 7 , and at 1,3 , and 6 months later. Samples were centrifuged ( $3000 \mathrm{~g}$ for 20 minutes), and the supernatant was carefully removed and stored at $-80^{\circ} \mathrm{C}$, and then thawed at room temperature just before the assays. Plasma MMP and TIMP-1 concentrations were measured by using a quantitative sandwich enzyme-linked immunosorbent assay (ELISA) test (Amersham International, Little Chalfont, UK), according to the manufacturer's guidelines. All samples were measured as duplicates; the mean was calculated for data analysis and matched with the normal plasma values of MMP-3, MMP-9, and TIMP-1 with an ELISA test (ie, 12.5-350 ng/mL, 0.25-200 ng/mL, and $0.15-30 \mathrm{ng} / \mathrm{mL}$, respectively).

Eligibility criteria for EVAR were aneurysm diameter more than $6.0 \mathrm{~cm}$ and/or documented aneurysm growth more than 0.5 $\mathrm{cm}$ in the last 12 months. Exclusion criteria for EVAR candidates were proximal aortic neck diameter larger than $4.4 \mathrm{~cm}$ or length of nonaneurysmal aorta from the origin of the left subclavian artery to the proximal attachment site less than $1.5 \mathrm{~cm}$. Details of the endovascular procedure have been reported. ${ }^{14}$

All patients had a Talent stent-graft (Medtronic Inc, Santa Rosa, Calif) with a mean of $2.2 \pm 0.7$ stent-graft per patient. Primary procedural success was defined as the absence of death or surgical conversion, exclusion of aneurysm or transected tract, occlusion of thoracic tear, and technically successful deployment of the endoprosthesis at the intended target location.

Early mortality and morbidity were considered as events occurring on the same hospital admission or within 30 days of the procedure. Late mortality included all deaths after 30 days. Any death that occurred suddenly or could not be related to other causes was classified as due to aortic disease.

Endoleaks, a specific complication of EVAR procedure, are defined as blood flow outside the lumen of the stent graft but within the aneurysm sac and were classified as early, when detected immediately after the endovascular procedure, and late, when developed de novo during the follow-up.

The follow-up ranged from 12 to 36 months (mean $24.5 \pm 7.3$ months) and included a clinical examination and standard labora- 


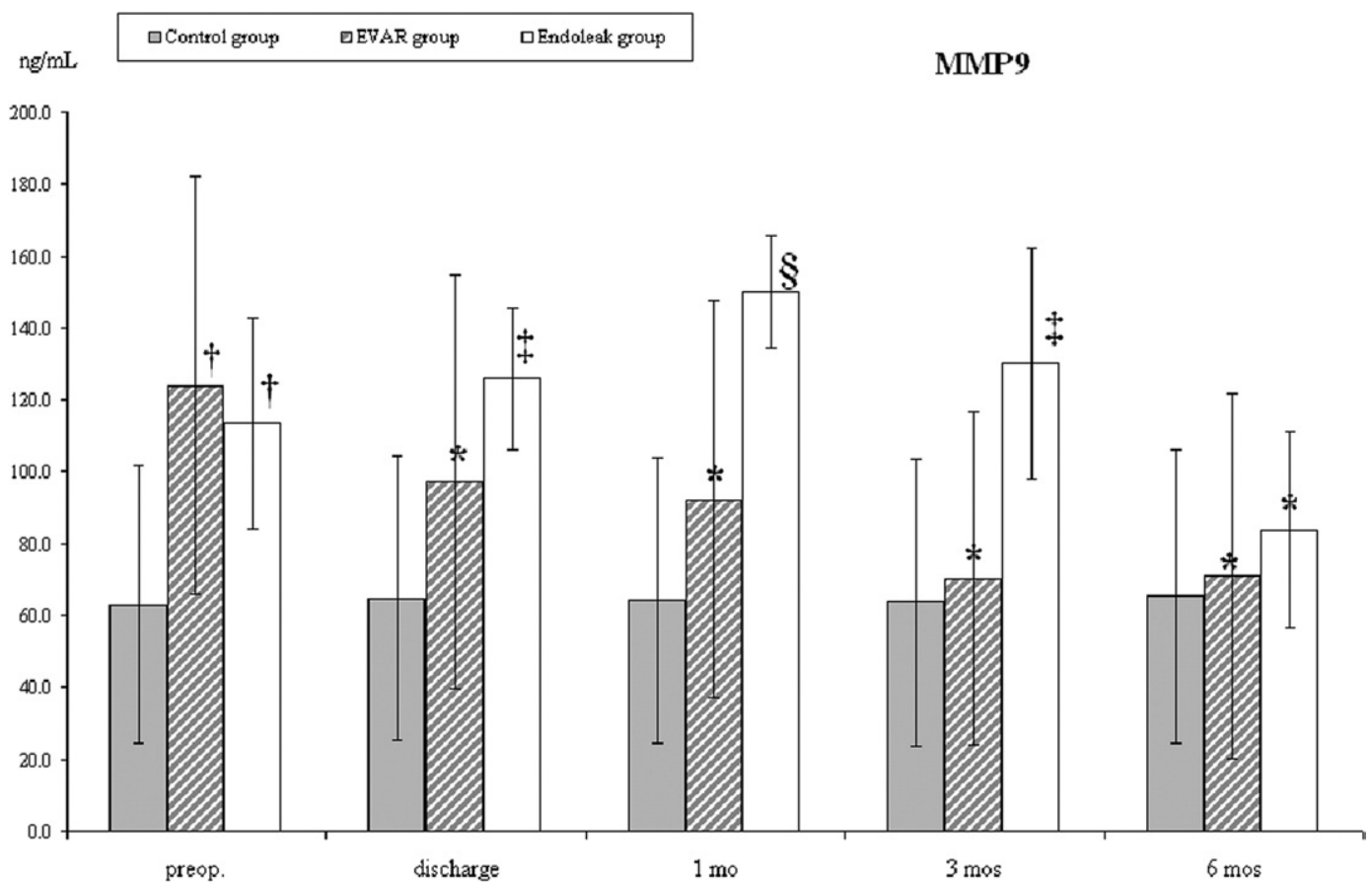

Figure 2. MMP-9 plasma value concentrations before and during follow-up after stent-graft placement. *Not significant; $\dagger<.05 ; \ddagger<.01 ; \S<.001$. EVAR, Endovascular aneurysm repair; MMP, matrix metalloproteinase.

tory test with MMP and TIMP-1 plasma level determinations. Thoracic and abdominal aorta CT scans, to detect the efficacy of the EVAR, were performed at the patient's discharge and at 1 and 6 months later.

\section{Statistical Analysis}

All data are presented as mean \pm standard deviation. The Pearson chi-square test was used to assess differences for clinical variables between the EVAR and control groups. A Mann-Whitney $U$ test was used to assess differences between the groups for the same variable, and repeated-measures analysis of variance was used to assess the differences between and within the groups at different times. Univariate linear regression analysis and Pearson correlation coefficient $(r)$ were used to identify any significant correlation between MMP and TIMP-1 plasma levels and aneurysmal maximum diameters. Data were analyzed by the Statistical Package for the Social Sciences 12.01 for Windows (SPSS Inc, Chicago, Ill).

\section{Results}

There were no hospital deaths. EVAR was successfully performed in all patients in accordance with the previously defined criteria. There were no cases of paraplegia or neurologic complications. The mean procedure time was $110.6 \pm 27.5$ minutes (range $72-175$ minutes), loss of blood was minimal, and no patient required any transfusion. The mean length of hospital stay was $5.1 \pm 1.2$ days (range 4-10 days).
There were no late deaths. At the 1-month CT scan, 4 endoleaks were identified in 4 patients (12.5\%): 2 patients had a proximal type I endoleak $(6.2 \%), 1$ patient required a secondary EVAR 1 month later and the other resolved spontaneously within 6 months; the remaining 2 patients, with type II endoleaks caused by retrograde flow from intercostal arteries, showed flow reduction and no expansion of the aneurysmal sac at the later follow-up. After stent graft placement and during follow-up, plasma value concentrations of MMP-3 and MMP-9, and MMP-9/TIMP-1 ratio significantly decreased in patients showing no endoleak compared with preoperative values (repeated-measures analysis of variance test, $P=.001, .001$, and .01 , respectively), whereas TIMP-1 plasma values significantly increased $(P=.001)$, especially in patients with endoleaks $(P=.001)$. At the same time, these changes were not significant in patients with endoleaks.

In control group B, plasma concentrations of MMP-3, MMP-9, and TIMP-1 were not correlated to age $\left(\mathrm{r}_{\mathrm{s}}=\right.$ -0.196-0.109) and were not different between female and male controls (Mann-Whitney $U$ test, $P=$ not significant). Control group B data were then compared with the results of patients with descending TAAs who had undergone EVAR (group A). The results are summarized in Table 2. The mean preoperative plasma values for MMP-3, MMP-9, and MMP-9/TIMP-1 ratio in group A were significantly higher 


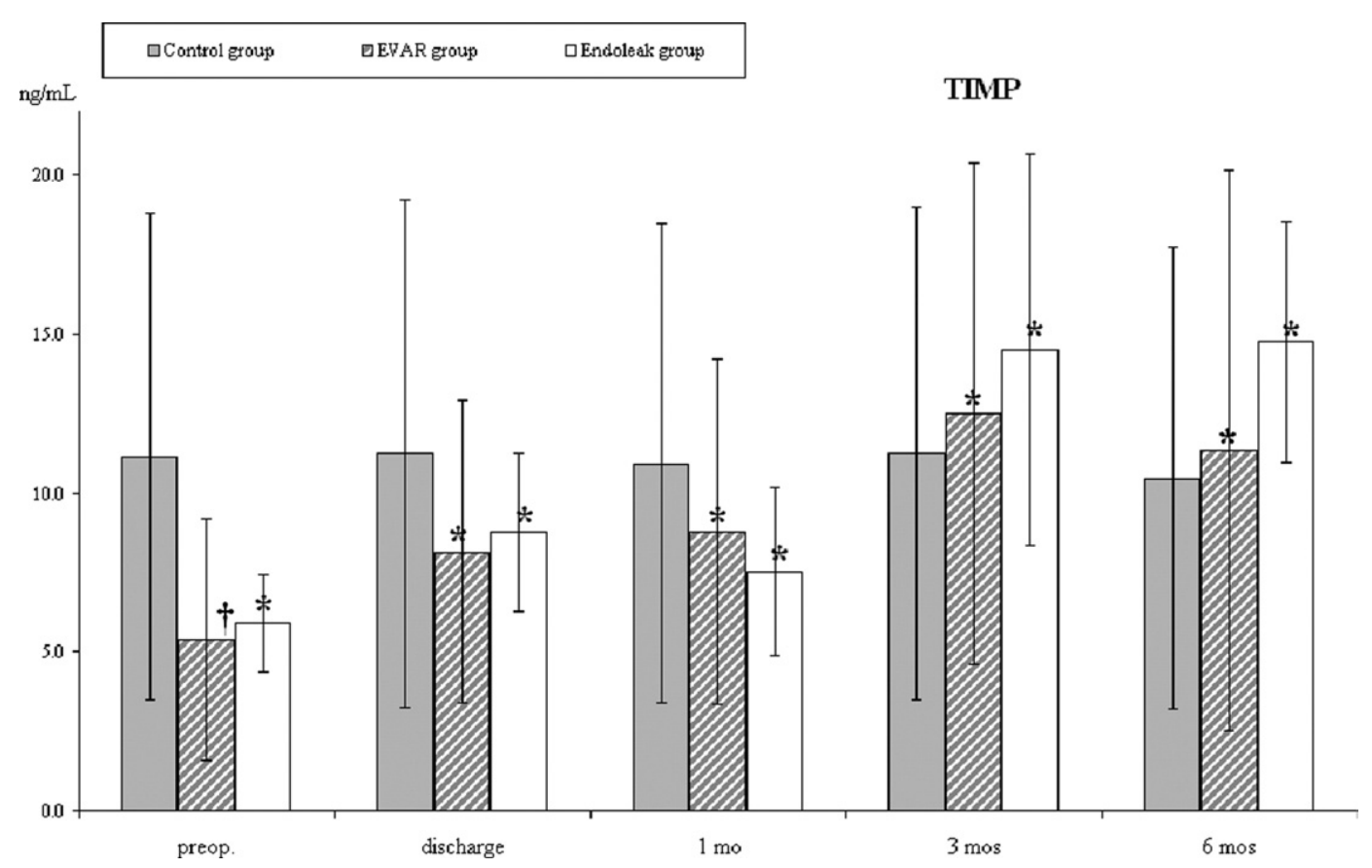

Figure 3. TIMP-1 plasma value concentrations before and during follow-up after stent-graft placement. *Not significant; $\dagger<.05$; $<.01 ; \S<.001$. EVAR, Endovascular aneurysm repair; TIMP, tissue inhibitor of metalloproteinases.

than those in group $\mathrm{B}(P<.001,=.02$, and $=.003$, respectively), whereas the mean preoperative plasma value for TIMP-1 was significantly lower than in group B $(P=$ .04). At 1 month follow-up, only the MMP-9/TIMP-1 ratio between the 2 groups reached statistical significance $(P=$ $.01)$. At the 6-month follow-up all values studied were similar in both groups.

The 4 patients with endoleaks showed an increase of MMP-3 and MMP-9 at the 1-month follow-up $(P=.002$ and .02 vs group A, respectively; $P=.003$ and $<.001$ vs group $\mathrm{B}$, respectively), which slightly persisted only for MMP-9 at the 6-month follow-up, when a clinical improvement of the endoleaks was also observed $(P=.04)$. In patients with endoleaks, the MMP-9/TIMP-1 ratio increased, compared with both EVAR and control groups, at discharge and at 1 month $(P=.008$ and .02 , respectively), reaching normal values at 6 months. The plasma value concentrations preoperatively, after EVAR, and during follow-up, and in control patients, are shown in Figures 1, 2, 3, and 4.

\section{Discussion}

The main cause of descending TAAs is atherosclerosis, and the pathogenesis of such atherosclerotic aneurysms may resemble that of AAAs. The aortic wall resists dilatation because of the strength of its ECM components, notably elastin and collagen. The MMPs, degrading the ECM, play a central role in the pathogenesis of atherosclerotic aneu- rysms. ${ }^{5}$ Several members of the MMP family have been implicated in the pathogenesis of aortic aneurysms, including stromelysin (MMP-3) and gelatinase B (MMP-9). In mouse models of atherosclerosis, macrophage-derived MMPs (MMP-3, 9, and 12) triggered elastolysis and collagenolysis, resulting in media destruction and thus aneurysm formation. ${ }^{15,16}$ MMP-3 and MMP-9 are well present in the wall of AAAs, ${ }^{7,8}$ and the role of MMP-9 in aneurysm formation has been addressed. ${ }^{10,17}$ MMP-9, released from inflammatory cells, is significantly elevated in the aneurysm walls; the levels of MMP-9 messenger RNA expression are 4-fold higher in large aneurysms $(5.0-6.9 \mathrm{~cm})$ compared with small aneurysms $(3.0-4.9 \mathrm{~cm}){ }^{18}$

An imbalance between MMPs and TIMPs may tip the equilibrium toward matrix degradation, thus influencing aneurysm development. Tamarina and colleagues, ${ }^{19}$ who studied messenger RNA levels for MMPs and TIMPs in aneurysms and normal aorta, demonstrated the predominant role of MMP-9 and TIMP-1 in the aneurysm group. Moreover, TIMP-1-deficient mice, in which experimental aneurysm formation was induced, had an increase in abdominal and thoracic aneurysm size. ${ }^{20,21}$

We prospectively studied the changes in MMP-3, MMP-9, and TIMP-1 plasma levels in a consecutive series of patients with TAAs who had undergone EVAR (group A) and matched them with a control group of healthy patients (group B). Moreover, we studied the MMP-9/TIMP-1 ratio 


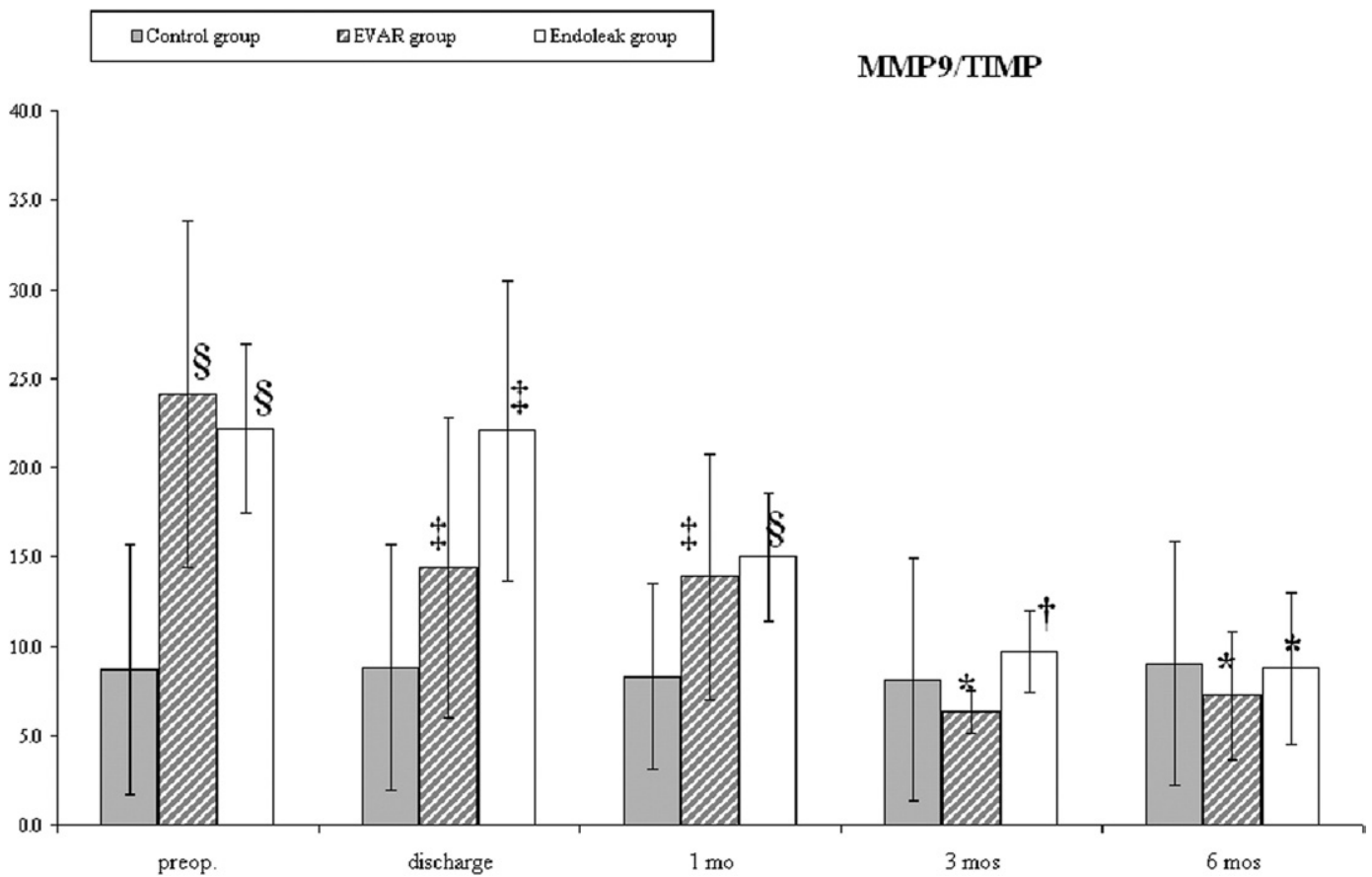

Figure 4. MMP-9/TIMP-1 ratio before and during follow-up after stent-graft placement. *Not significant; $\dagger<.05$; $\ddagger<.01 ; \S<.001$. EVAR, Endovascular aneurysm repair; MMP, matrix metalloproteinase; TIMP, tissue inhibitor of metalloproteinases.

as a reliable marker of shifting from an overall proteolytic state to a more homeostatic one. The increased preoperative plasma levels of MMP-3 and MMP-9 that we observed in group A compared with group B may confirm the relation between active ECM catabolism and aneurysm progression. These data, widely known for AAAs, have scarcely been examined in patients with descending TAAs. ${ }^{10-12}$ Our results seem to confirm the similar pathophysiology for AAAs and TAAs and may prove useful in following patients treated by EVAR. To our knowledge, this report is the first to demonstrate changes in MMP-3 and 9 and TIMP-1 plasma levels in patients affected by descending TAAs who were successfully treated by EVAR and its clinical significance.

In agreement with other studies demonstrating a decrease in MMP levels after endovascular or surgical repair, ${ }^{6,7}$ our study demonstrated an early decrease of MMP-3 and an increase of TIMP-1 levels, with the MMP-9 decreasing more gradually. All of these values reached normality at the 6-month follow-up. We hypothesized that this difference in MMP-3 and MMP-9 decrease is the result of the postimplantation syndrome, as occurred in 5 of our patients, or the unspecific inflammatory reaction that always occurs after TAA surgery (both endovascular or open). Recently, Barbour and colleagues ${ }^{22}$ induced TAA formation in mice and demon- strated a biphasic changes in MMPs, with persistent high levels of MMP-9 in the late-phase response ascribed to chronic inflammatory reaction.

EVAR for descending TAAs has become a consolidated procedure, improving on short- and mid-term results of traditional surgical repair. ${ }^{23}$ Endoleak is a well-known complication of EVAR, and close postoperative surveillance and early endoleak management are critical to determine the long-term success of EVAR. Patients are usually followed up with serial CT scans, ${ }^{24}$ with significant increase in costs and radiation exposure. CT imaging alone is not always adequate in the clinical decision-making process, because the evaluation of only the aneurysmal diameter in the presence of an endoleak cannot exactly predict the outcome after endovascular TAA repair.

We found a relationship between the plasma MMP expression and the presence of an endoleak, and observed that MMP and TIMP-1 plasma levels follow the clinical pattern of patients with an endoleak. In patients with an endoleak, MMP and TIMP-1 plasma levels normalize at the 3- and 6-month follow-ups when adequate sealing, spontaneous resolution, and/or reduction of both type I and II endoleaks clinically occur. On the contrary, a persistence or an increase in MMP levels after EVAR may represent ineffective aneurysm exclusion. For this reason, we think that MMP and TIMP-1 assays in patient with endoleaks may be useful 
in avoiding expensive CT scan control, and an increase in plasma levels should indicate immediate treatment of the endoleaks. The MMP-9/TIMP-1 ratio, expression of protein synthetic-lytic equilibrium, seems to be a more accurate marker, with a trend reflecting the clinical outcome of patients with endoleaks.

Our data are preliminary and based on a small group of patients with endoleaks after EVAR. To obtain meaningful data, more patients with endoleaks are necessary, but this complication rarely occurs in experienced centers. ${ }^{25}$

\section{Conclusions}

Although our study involved a small sample of patients and low statistical power, it confirms that plasma MMP-3 and MMP-9 values are increased in patients with TAAs, along with reduced TIMP-1 expression. MMP plasma level determination could be used to monitor the success of therapeutic strategies for the treatment of TAAs: EVAR leads to plasma value normalization of these enzymes, whereas abnormally high levels are found in patients with endoleaks. The ELISA test is a simple, readily available, and reliable technique that may be used both to assess the efficacy of EVAR and to detect endoleaks, thus avoiding expensive serial CT scan control. Further studies are necessary before drawing precise conclusions.

\section{References}

1. Elefteriades JA. Natural history of thoracic aortic aneurysms: indications for surgery, and surgical versus nonsurgical risks. Ann Thorac Surg. 2002;74(Suppl):S1877-80; discussion S1892-8.

2. Zipes DP, Libby P, Bonow RO, Brauwald E. Braunwald's Heart Disease: A Textbook of Cardiovascular Medicine. 7th Edition. Philadelphia: Elsevier Saunders; 2005.

3. Lijnen HR. Plasmin and matrix metalloproteinases in vascular remodeling. Thromb Haemost. 2001;86:324-33.

4. Elmore JR, Keister BF, Franklin DP, Youkey JR, Carey DJ. Expression of matrix metalloproteinases and TIMPs in human abdominal aortic aneurysm. Ann Vasc Surg. 1998;12:221-8.

5. Keeling WB, Armstrong PA, Stone PA, Bandyk DF, Shames ML. An overview of matrix metalloproteinases in the pathogenesis and treatment of abdominal aortic aneurysms. Vasc Endovascular Surg. 2005; 39:457-64.

6. Sangiorgi G, D'Averio R, Mauriello A, Bondio M, Postillo M, Castelvecchio S, et al. Plasma levels of metalloproteinases-3 and -9 as markers of successful abdominal aortic aneurysm exclusion after endovascular graft treatment. Circulation. 2001;104(Suppl I):I-288-I295.

7. Taurino M, Visco V, Raffa S, Ricci B, Ruggiero M, Torrisi MR, et al. Matrix metalloproteinase 9 activity in patients before and after endovascular or surgical repair of abdominal aortic aneurysms. Vascular. 2004;12:312-7.

8. Carrell TW, Burnand KG, Wells GM, Clements JM, Smith A. Stromelysin-1 (matrix metalloproteinase-3) and tissue inhibitor of metalloproteinase- 3 are overexpressed in the wall of abdominal aortic aneurysms. Circulation. 2002;105:477-82.
9. Chen L, Wang X, Carter SA, Shen YH, Bartsch HR, Thompson RW, et al. A single nucleotide polymorphism in the matrix metalloproteinase 9 gene $(-8202 \mathrm{~A} / \mathrm{G})$ is associated with thoracic aortic aneurysms and thoracic aortic dissection. $J$ Thorac Cardiovasc Surg. 2006;131: 1045-52.

10. Koullias GJ, Ravichandran P, Korkolis DP, Rimm DL, Elefteriades JA. Increased tissue microarray matrix metalloproteinase expression favors proteolysis in thoracic aortic aneurysms and dissections. Ann Thorac Surg. 2004;78:2106-10.

11. Boyum J, Fellinger EK, Schmoker JD, Trombley L, McPartland K, Ittleman FP, et al. Matrix metalloproteinase activity in thoracic aortic aneurysms associated with bicuspid and tricuspid aortic valves. J Thorac Cardiovasc Surg. 2004;127:686-91.

12. Schmoker JD, McPartland KJ, Fellinger EK, Boyum J, Trombley L, Ittleman FP, et al. Matrix metalloproteinase and tissue inhibitor expression in atherosclerotic and nonatherosclerotic thoracic aortic aneurysms. J Thorac Cardiovasc Surg. 2007;133:155-61.

13. Magi E. ASA classification and perioperative variables as predictors of postoperative outcome. Br J Anaesth. 1997;78:228.

14. Monaco M, Di Tommaso L, Stassano P, Smimmo R, De Amicis V, Pantaleo A, et al. Impact of blood coagulation and fibrinolytic system changes on early and mid term clinical outcome in patients undergoing stent endografting surgery. Interact CardioVasc Thorac Surg. 2006;5: 724-8.

15. Longo GM, Xiong W, Greiner TC, Zhao Y, Fiotti N, Baxter BT. Matrix metalloproteinases 2 and 9 work in concert to produce aortic aneurysms. J Clin Invest. 2002;110:625-32.

16. Newman KM, Ogata Y, Malon AM, Irizarry E, Gandhi RH, Nagase H, et al. Identification of matrix metalloproteinases 3 (stromelysin-1) and 9 (gelatinase B) in abdominal aortic aneurysm. Arterioscler Thromb. 1994;14:1315-20

17. Thompson RW, Holmes DR, Mertens RA, Liao S, Botney MD, Mecham RP, et al. Production and localization of 92-kilodalton gelatinase in abdominal aortic aneurysms. An elastolytic metalloproteinase expressed by aneurysm-infiltrating macrophages. J Clin Invest. 1995; 96:318-26.

18. McMillan WD, Tamarina NA, Cipollone M, Johnson DA, Parker MA, Pearce WH. Size matters: the relationship between MMP-9 expression and aortic diameter. Circulation 1997;96:2228-32.

19. Tamarina NA, McMillan WD, Shively VP, Pearce WH. Expression of matrix metalloproteinases and their inhibitors in aneurysms and normal aorta. Surgery. 1997;122:264-71.

20. Ikonomidis JS, Gibson WC, Butler JE, McClister DM, Sweterlitsch SE, Thompson RP, et al. Effects of deletion of the tissue inhibitor of matrix metalloproteinases- 1 gene on the progression of murine thoracic aortic aneurysms. Circulation. 2004;110(Suppl):II268-73.

21. Eskandari MK, Vijungco JD, Flores A, Borensztajn J, Shively V, Pearce WH. Enhanced abdominal aortic aneurysm in TIMP-1-deficient mice. J Surg Res. 2005;123:289-93.

22. Barbour JR, Stroud RE, Lowry AS, Clark LL, Leone AM, Jones JA, et al. Temporal disparity in the induction of matrix metalloproteinases and tissue inhibitors of metalloproteinases after thoracic aortic aneurysm formation. J Thorac Cardiovasc Surg. 2006;132:788-795.

23. Cho JS, Haider SE, MD, Makaroun MS. US multicenter trials of endoprostheses for the endovascular treatment of descending thoracic aneurysms. J Vasc Surg. 2006;43(Suppl A):12A-19A.

24. Stavropoulos SW, Carpenter JP. Postoperative imaging surveillance and endoleak management after endovascular repair of thoracic aortic aneurysms. J Vasc Surg. 2006;43(Suppl A):12A-19A.

25. Fattori R, Nienaber CA, Rousseau H, Beregi JP, Heijmen R, Grabenwoger M, et al; Talent Thoracic Retrospective Registry. Results of endovascular repair of the thoracic aorta with the Talent Thoracic stent graft: the Talent Thoracic Retrospective Registry. J Thorac Cardiovasc Surg. 2006;132:332-9. 